\title{
On the Reactive Uptake of Gaseous Compounds by Organic-Coated Aqueous Aerosols: Theoretical Analysis and Application to the Heterogeneous Hydrolysis of $\mathrm{N}_{2} \mathrm{O}_{5}$
}

\author{
Tatu Anttila, ${ }^{\dagger}$ Astrid Kiendler-Scharr, Ralf Tillmann, and Thomas F. Mentel* \\ ICG-II: Troposphäre, Forschungszentrum Jülich, 52425 Jülich, Germany
}

Received: April 19, 2006; In Final Form: July 3, 2006

\begin{abstract}
The presence of organic coatings on aerosols may have important consequences to the atmospheric chemistry, in particular to the $\mathrm{N}_{2} \mathrm{O}_{5}$ heterogeneous hydrolysis. This is demonstrated by recent experiments which show that the uptake of $\mathrm{N}_{2} \mathrm{O}_{5}$ by aqueous aerosols is slowed considerably when an organic coating consisting of monoterpene oxidation products is added on the particles. To treat the mechanisms behind the suppression, an extension of the resistor model, which has been widely applied in investigation of the heterogeneous uptake by aerosols, was derived. The extension accounts for dissolution, diffusion, and chemical reactions in a multilayered organic coating, and it provides a parametrization for the heterogeneous uptake by organiccoated aerosols that can be applied in large-scale models. Moreover, the framework was applied to interpret the findings regarding the decreased uptake of $\mathrm{N}_{2} \mathrm{O}_{5}$ by the organic-coated aerosols. Performed calculations suggested that the reaction rate constant of $\mathrm{N}_{2} \mathrm{O}_{5}$ in the coating is decreased by $3-5$ orders of magnitude, in addition to which the product of the solubility of $\mathrm{N}_{2} \mathrm{O}_{5}$ and its diffusion coefficient in the coating is reduced more than an order of magnitude compared to the corresponding value for the aqueous phase. The results suggest also that the accommodation coefficient of $\mathrm{N}_{2} \mathrm{O}_{5}$ to such coatings is no more than a factor of 2 smaller than that to pure water surfaces. Finally, the relevance of the results to the atmospheric $\mathrm{N}_{2} \mathrm{O}_{5}$ heterogeneous hydrolysis is discussed and implications to planning further laboratory studies focusing on secondary organic aerosol formation are pointed out.
\end{abstract}

\section{Introduction}

One of the main sources of uncertainty in the current predictions concerning climate change arises from our inability to predict reliably the microphysical structure of atmospheric clouds, in particular the number and size of cloud droplets., 1,2 Since atmospheric aerosol particles act as nuclei onto which cloud droplets are formed, the cloud microphysical properties are sensitive to the number, size, and chemical composition of atmospheric aerosols. ${ }^{2,3}$ The last property is probably most poorly characterized despite numerous studies dedicated to identification and classification of aerosol phase compounds. What makes the topic challenging is the large diversity of organic compounds present in the atmosphere, and consequently the net effect of organics on the climatically relevant properties of atmospheric aerosols is still unclear., 4

One open question related to atmospheric organic compounds is their distribution in mixed inorganic/organic aerosols. The question arises because some atmospheric organics exhibit surface activity, i.e., they tend to partition into an air/water interface, and are thus able to concentrate on the aerosol surfaces. As mounting evidence shows, this may lead to a formation of organic coatings. It has been proposed, for example, that freshly formed marine aerosols contain a hydrophobic monolayer (a so-called inverted micelle) that is formed by amphiphilic fatty acid molecules residing on the ocean surfaces. ${ }^{6}$ The hypothesis is supported by observations of Tervahattu and co-workers, ${ }^{7,8}$ Mochida et al. ${ }^{9}$, and Russell et al. ${ }^{10}$ Long-chain fatty acids have also been observed on the surfaces of continental

$\dagger$ Current address: Finnish Meteorological Institute, Research and Development, Climate and Global Change, P.O. Box 503, 00101 Helsinki, Finland. sulfate particles. ${ }^{11}$ Moreover, aqueous particles may acquire a coating in the atmosphere through condensation of low-volatile vapors with a biogenic origin. ${ }^{12,13}$ Such coatings are probably hydrophobic, and their thickness is not limited to that of a monolayer but is controlled by the availability of condensing vapors.

The presence of organic coatings on atmospheric aerosols is suggested to have implications regarding atmospheric chemistry and cloud microphysics., ${ }^{5,12,14,17}$ One particular mechanism underlying these effects is an inhibition of mass transfer between the gas phase and particles. The retardation might be caused by a reduced mass accommodation of molecules to the organic surface, a decreased solubility into the organic phase, and/or mass transfer limitations caused by diffusion through the coating. In this regard, nonreactive and reactive compounds should be distinguished, since even though an organic coating may not influence mass transfer of nonreactive compounds (e.g., water), it may inhibit the uptake of reactive compounds. This is because molecules consumed in fast particle phase reactions need to be rapidly replenished in order to maintain the overall reaction rate, and therefore even a small decrease in the flux of gaseous precursors may slow the reactive uptake. Influence of organic coatings on mass transfer of nonreactive compounds, including water, has been investigated theoretically and via model simulations ${ }^{5,14,16}$ but a similar study considering reactive compounds is to our best knowledge lacking.

The reactive uptake of gaseous compounds by aerosols can be treated using a so-called resistor model, here termed as a traditional resistor model, which has been widely applied in analyzing data from laboratory experiments and in reactive uptake parametrizations for large-scale models. ${ }^{18-22}$ Since the 
traditional resistor model assumes that aerosols contain a single bulk phase, we extend the formalism to cover aerosols with an organic coating. We focus on coatings that are thick enough to be considered as bulk absorbing phases, in contrast to monolayers or submonolayers of which effects have been investigated experimentally by Thornton and $\mathrm{Abbatt}^{23}$ and McNeill et al. ${ }^{24}$ While the extended model lacks the generality of that presented by Pöschl et al., ${ }^{25}$ it explicitly accounts for the above-mentioned retardation mechanisms and can be applied directly to organiccoated aerosols.

The paper is organized as follows. We first present the background of the approach and then derive the formalism following closely the derivation of the traditional resistor model (sections 2.1 and 2.2). In section 2.3, we explore the conditions under which dissolution and diffusion in the organic coating becomes the rate-limiting step in the reactive uptake. We also apply the developed model to explain our recent experimental findings regarding decreased uptake of $\mathrm{N}_{2} \mathrm{O}_{5}$ by aqueous sulfate aerosols coated with monoterpene oxidation products (section 3 ), and discuss the implications of the experimental results and their interpretation (section 4). Finally, conclusions and summary are given in section 5 .

\section{Theory}

The uptake coefficient $\gamma$ of a gas-phase reactive compound can be defined in terms of the molar flux, $J_{\mathrm{gas}}$, of the reactant into a particle: ${ }^{20}$

$$
J_{\text {gas }}=\frac{\gamma}{4} A_{\mathrm{p}} C_{\mathrm{gas}}\langle c\rangle
$$

where $A_{\mathrm{p}}\left(\mathrm{m}^{2}\right)$ is the particle surface area, $C_{\mathrm{gas}}\left(\mathrm{mol} / \mathrm{m}^{3}\right)$ is the reactant gas-phase concentration, and $\langle c\rangle(\mathrm{m} / \mathrm{s})$ is the average velocity of the reactant in the gas phase. The quantity $J_{\text {gas }}$ can also be expressed as the following: ${ }^{20}$

$$
J_{\text {gas }}=V_{\mathrm{p}} k_{\mathrm{mt}}\left(C_{\mathrm{gas}}-\frac{C\left(R_{\mathrm{p}}\right)}{R T H}\right)
$$

Here $V_{\mathrm{p}}\left(\mathrm{m}^{3}\right)$ is the particle volume, $k_{\mathrm{mt}}\left(\mathrm{s}^{-1}\right)$ is a mass transfer coefficient that accounts for both gas-phase diffusion and mass accommodation, $C\left(R_{\mathrm{p}}\right)\left(\mathrm{mol} / \mathrm{m}^{3}\right)$ is the reactant concentration just below the particle surface, $R$ is the ideal gas constant, $T$ $(\mathrm{K})$ is the ambient temperature, and $H\left(\mathrm{~mol} / \mathrm{m}^{3} / \mathrm{atm}\right)$ is the Henry's law constant.

The value of $\gamma$ can be determined experimentally using eq 1 provided that the total particle surface area, reactant gas-phase concentration, and $J_{\text {gas }}$ are measured precisely. However, eq 1 does not give any information on the processes behind the reactive uptake, and therefore it cannot be applied in interpreting measured data or predicting the uptake rates in, e.g., regional or global models. In particular, possible mass transfer limitations caused by organic coatings cannot be addressed using eq 1 . Therefore, we seek an expression for $\gamma$ that would contain only measurable quantities and where the processes involved in the reactive uptake, including those taking place in an organic coating, are deconvoluted as far as possible. We approach the problem by deriving a suitable expression for $C\left(R_{\mathrm{p}}\right)$, substituting it to eq 2 and solving eq 1 with aid of the obtained equation.

We consider spherical particles that contain two absorbing phases: an aqueous spherical core and an organic, liquidlike layer that surrounds the core. We assume that particle phase reactions are induced by a single gaseous reactant and that the reactions follow first-order kinetics. The assumption implies that the particle phase concentrations of other compounds involved in the reactions are constant, which may not hold for large, viscous particles and for large reactant gas-phase concentrations. ${ }^{26,27}$ To assess quantitatively under which conditions the assumption is valid, a numerical solution of the diffusionreaction equations is required. ${ }^{27}$ This is beyond the scope of this study; here, our focus is to provide an analytical expression for the uptake coefficient. Furthermore, we suppose that the system is in a steady-state, e.g., the time derivate of the reactant concentration is set equal to zero. Finally, the Kelvin effect is neglected since it has importance only for extremely small particles with diameters $<10 \mathrm{~nm}^{28}$ If needed, however, the Kelvin effect can be readily accounted for by dividing the appropriate gas/particle partitioning constant with the Kelvin term. ${ }^{28}$

The above-stated problem is solved in section 2.1, after which we derive an approximate expression for $\gamma$ in order to facilitate interpretation of experimental data, provide a simple parametrization for large-scale models, and better elucidate the impact of organic coatings on the reactive uptake (section 2.2). We also examine under which conditions organic coatings affect the rate of heterogeneous reactions and assess the validity of the approximate expression (section 2.3).

2.1. General Case. In the considered case, the reactant particle phase concentration, $C$, is only a function of the distance from the particle center, $r$, and is governed by the following equation:

$$
\frac{1}{r^{2}} \frac{\mathrm{d}}{\mathrm{d} r}\left(r^{2} D \frac{\mathrm{d} C}{\mathrm{~d} r}\right)-k C=0
$$

where $D\left(\mathrm{~m}^{2} / \mathrm{s}\right)$ is the diffusion coefficient and $k\left(\mathrm{~s}^{-1}\right)$ is the first-order reaction rate constant. The parameters $D$ and $k$ are modeled here using a step function so that they have constant but possibly different values in the coating and in the aqueous phase. Such a description is simplified, but postulating an interface region where the parameters vary (e.g., linearly) leads to such solutions for $C$ that cannot be expressed in a closed form and thus prohibits a derivation of the analytical equation for the uptake coefficient.

Equation 3 can be solved by substituting $C=Z / r$ :

$$
\begin{aligned}
& C(r)=A^{-} \frac{\sinh \left(\frac{r q_{\mathrm{aq}}}{R_{\mathrm{c}}}\right)}{r}+B^{-} \frac{\cosh \left(\frac{r q_{\mathrm{aq}}}{R_{\mathrm{c}}}\right)}{r}, 0 \leq r<R_{\mathrm{c}} \\
& C(r)=A^{+} \frac{\sinh \left(\frac{r q_{\mathrm{org}}}{R_{\mathrm{p}}}\right)}{r}+B^{+} \frac{\cosh \left(\frac{r q_{\mathrm{org}}}{R_{\mathrm{p}}}\right)}{r}, \quad R_{\mathrm{c}} \leq r \leq R_{\mathrm{p}} \\
& q_{\mathrm{aq}}=R_{\mathrm{c}} \sqrt{\frac{k_{\mathrm{aq}}}{D_{\mathrm{aq}}}}, \quad q_{\mathrm{org}}=R_{\mathrm{p}} \sqrt{\frac{k_{\text {org }}}{D_{\text {org }}}}
\end{aligned}
$$

Here $A^{-}, B^{-}, A^{+}$, and $B^{+}$are constants, $R_{\mathrm{c}}$ is the radius of the aqueous core, $k_{\mathrm{aq}}$ and $k_{\text {org }}$ are the reaction rate constants for the aqueous phase and the organic coating, respectively, and $D_{\text {aq }}$ and $D_{\text {org }}$ are the diffusion coefficients of the reactant in the aqueous phase and in the organic coating, respectively (Figure $1)$. The parameters $q_{\text {aq }}$ and $q_{\text {org }}$ are so-called diffuso-reactive parameters which describe competition between diffusion and reaction in the aqueous phase and organic coating, respectively.

Equation 4 contains four unknowns: $A^{-}, B^{-}, A^{+}$, and $B^{+}$. To express $C\left(R_{\mathrm{p}}\right)$ in terms of known parameters, four boundary conditions are thus needed. The first one follows from the spherical symmetry: the derivative of $C$ must vanish at the 


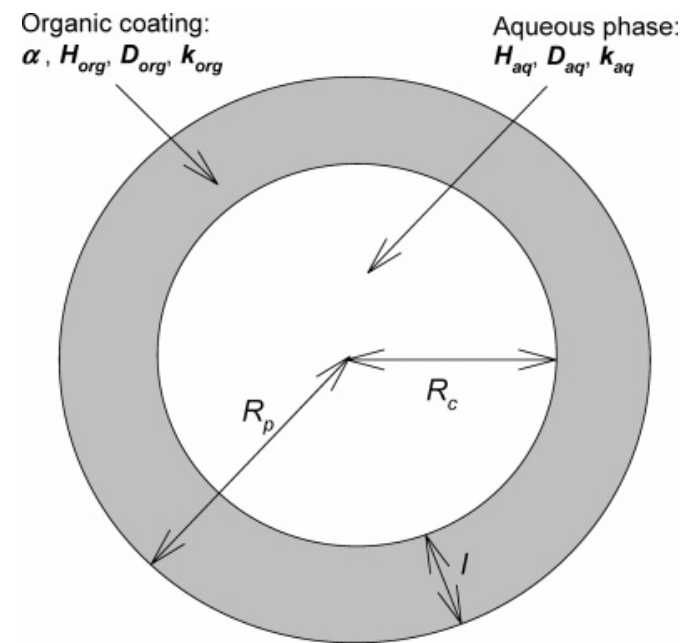

Figure 1. Schematic figure illustrating the role of various model parameters.

particle center. We also assume that the reactant is in a thermodynamic equilibrium at the core/coating interface, and the remaining two boundary conditions arise from the continuity of the reactant flux across the core/coating and coating/air interfaces. Taken together, we obtain the following boundary conditions:

$$
\begin{gathered}
\left.\frac{\mathrm{d} C}{\mathrm{~d} r}\right|_{r=0}=0 \\
C\left(R_{\mathrm{c}}\right)^{-}=\frac{H_{\mathrm{aq}}}{H_{\mathrm{org}}} C\left(R_{\mathrm{c}}\right)^{+} \\
\left.D_{\mathrm{aq}} \frac{\mathrm{d} C}{\mathrm{~d} r}\right|_{r=R_{\mathrm{c}}^{-}}=\left.D_{\mathrm{org}} \frac{\mathrm{d} C}{\mathrm{~d} r}\right|_{r=R_{\mathrm{c}}{ }^{+}} \\
\left.A_{\mathrm{p}} D_{\mathrm{org}} \frac{\mathrm{d} C}{\mathrm{~d} r}\right|_{r=R_{\mathrm{p}}}=V_{\mathrm{p}} k_{\mathrm{mt}}\left(C_{\mathrm{gas}}-\frac{C\left(R_{\mathrm{p}}\right)}{R T H_{\mathrm{org}}}\right)
\end{gathered}
$$

Here $C\left(R_{\mathrm{c}}\right)^{+}$and $C\left(R_{\mathrm{c}}\right)^{-}$are the reactant concentrations just above and below the core/coating interface, respectively, and $H_{\text {org }}$ and $H_{\text {aq }}$ are the Henry's laws constant of the reactant for the organic and aqueous phases, respectively.

The system of eq 4 can be solved using eq 5 to yield the following expression for $C\left(R_{\mathrm{p}}\right)$ :

$$
\begin{gathered}
C\left(R_{\mathrm{p}}\right)=\frac{C_{\mathrm{gas}}}{\frac{3 D_{\mathrm{org}}}{k_{\mathrm{mt}} R_{\mathrm{p}}^{2}}\left(q_{\mathrm{org}} F-1\right)+\frac{1}{R T H_{\mathrm{org}}}} \\
F=\frac{\operatorname{coth}\left(q_{\mathrm{org}}\right)+h\left(q_{\mathrm{aq}}, q_{\mathrm{org}}^{*}\right)}{1+\operatorname{coth}\left(q_{\mathrm{org}}\right) h\left(q_{\mathrm{aq}}, q_{\mathrm{org}}^{*}\right)} \\
h\left(q_{\mathrm{aq}}, q_{\mathrm{org}}^{*}\right)=-\tanh \left(q_{\mathrm{org}}^{*}\right) \\
{\left[\frac{H_{\mathrm{aq}} D_{\mathrm{aq}}}{H_{\mathrm{org}} D_{\mathrm{org}}}\left(q_{\mathrm{aq}} \operatorname{coth}\left(q_{\mathrm{aq}}\right)-1\right)-\left(q_{\mathrm{org}}^{*} \operatorname{coth}\left(q_{\mathrm{org}}^{*}\right)-1\right)\right.} \\
\frac{H_{\mathrm{aq}} D_{\mathrm{aq}}}{H_{\mathrm{org}} D_{\mathrm{org}}}\left(q_{\mathrm{aq}} \operatorname{coth}\left(q_{\mathrm{aq}}\right)-1\right)-\left(q_{\mathrm{org}}^{*} \tanh \left(q_{\mathrm{org}}^{*}\right)-1\right) \\
q_{\mathrm{org}}^{*}=\frac{R_{\mathrm{c}}}{R_{\mathrm{p}}} q_{\mathrm{org}}
\end{gathered}
$$

Combining eq 6 with eq 2 and substituting the resulting equation for $J_{\text {gas }}$ to eq 1 we obtain

$$
\frac{1}{\gamma}=\langle c\rangle\left(\frac{3}{4 k_{\mathrm{mt}} R_{\mathrm{p}}}+\frac{R_{\mathrm{p}}}{4 R T H_{\mathrm{org}} D_{\mathrm{org}}\left(q_{\mathrm{org}} F-1\right)}\right)
$$

The applied expression for $k_{\mathrm{mt}}$ is the following: ${ }^{20}$

$$
k_{\mathrm{mt}}=\left[\frac{R_{\mathrm{p}}^{2} R T}{3 D_{\mathrm{gas}}}+\frac{4 R T R_{\mathrm{p}}}{3 \alpha\langle c\rangle}\right]^{-1}
$$

Substituting this into eq 7 yields

$$
\frac{1}{\gamma}=\frac{\langle c\rangle R_{\mathrm{p}}}{4 D_{\mathrm{gas}}}+\frac{1}{\alpha}+\frac{\langle c\rangle R_{\mathrm{p}}}{4 R T H_{\mathrm{org}} D_{\mathrm{org}}\left(q_{\mathrm{org}} F-1\right)}
$$

where $\alpha$ is the mass accommodation coefficient of the reactant and $D_{\text {gas }}$ is its gas-phase diffusion coefficient. The first, second, and third terms in the right-hand side of eq 9 account for gasphase diffusion, mass accommodation, and bulk phase processes (dissolution, diffusion, and chemical reactions), respectively. It is seen that eq 9 is similar to the traditional resistor model, ${ }^{18,20}$ and in the next section, we demonstrate that eq 9 reduces to the traditional resistor formalism when particles do not contain a coating.

The first term in the right-hand side of eq 9 is valid only in the continuum transport regime, but if needed, it can be readily replaced by a term that is valid also in the kinetic and transition regimes. ${ }^{22,26}$

It should be also noted that the functions $\operatorname{coth}\left(q_{\text {org }}\right)$ and $h$ in eq 6 approach rapidly 1 and -1 with increasing $q_{\text {aq }}$ and $q_{\text {org }}$, respectively. Consequently both the numerator and denominator of $F$ approach zero, which complicates or even prohibits numerical evaluation of the function. It can be demonstrated, however, that $F$ approaches unity at this limit, and therefore $F$ can be set equal to its limiting value when $q_{\text {aq }}$ and $q_{\text {org }}$ have values too large to enable numerical evaluation.

2.2. Weakly or Nonreactive Coatings. As noted above, the processes taking place in the organic coating and the aqueous phase are treated by the same term in eq 9. To decouple the treatment of these two phases, we consider a case where chemical reactions taking place in the coating proceed considerably slower than diffusion, i.e., $q_{\text {org }} \ll 1$. By expanding the hyperbolic functions contained by the function $F$ to Taylor series with respect to $q_{\text {org }}$ and by retaining only the first-order terms we obtain

$$
q_{\mathrm{org}} F-1 \approx \frac{R_{\mathrm{c}} / R_{\mathrm{p}}}{\frac{l}{R_{\mathrm{p}}}+\frac{H_{\mathrm{org}} D_{\mathrm{org}}}{H_{\mathrm{aq}} D_{\mathrm{aq}}\left[q_{\mathrm{aq}} \operatorname{coth}\left(q_{\mathrm{aq}}\right)-1\right]}}
$$

where $l$ is the coating thickness. Consequently we obtain the following approximation for $\gamma$ :

$$
\begin{gathered}
\frac{1}{\gamma}=\frac{\langle c\rangle R_{\mathrm{p}}}{4 D_{\mathrm{gas}}}+\frac{1}{\alpha}+\frac{1}{\Gamma_{\mathrm{aq}}}+\frac{1}{\Gamma_{\text {coat }}} \\
\frac{1}{\Gamma_{\mathrm{aq}}}=\frac{\langle c\rangle}{4 R T H_{\mathrm{aq}} D_{\mathrm{aq}} Q} \frac{R_{\mathrm{p}}{ }^{2}}{R_{\mathrm{c}}}, \frac{1}{\Gamma_{\text {coat }}}=\frac{\langle c\rangle l}{4 R T H_{\mathrm{org}} D_{\text {org }}} \frac{R_{\mathrm{p}}}{R_{\mathrm{c}}}
\end{gathered}
$$

where $Q=q_{\mathrm{aq}} \operatorname{coth}\left(q_{\mathrm{aq}}\right)-1$. The aqueous and organic phases are treated by the third and fourth terms in the right-hand side of eq 11, respectively. At the limit $l=0$, i.e., when $R_{\mathrm{c}}=R_{\mathrm{p}}$, $1 / \Gamma_{\text {coat }}$ vanishes, and the resulting expression for $\gamma$ is seen to 
TABLE 1: Parameter Range Explored in Comparing the Various Expressions for the Reactive Uptake Coefficient (Section 2.3)

\begin{tabular}{cll}
\hline parameter & $\begin{array}{c}\text { minimum } \\
\text { value }\end{array}$ & $\begin{array}{c}\text { maximum } \\
\text { value }\end{array}$ \\
\hline$R_{\mathrm{p}}$ & $10 \mathrm{~nm}$ & $1 \mu \mathrm{m}$ \\
$l$ & $(0.01) R_{\mathrm{p}}$ & $(0.9) R_{\mathrm{p}}$ \\
$D_{\text {org }}$ & $10^{-11} \mathrm{~m}^{2} / \mathrm{s}$ & $10^{-9} \mathrm{~m}^{2} / \mathrm{s}$ \\
$H_{\mathrm{aq}}$ & $0.1 \mathrm{M} / \mathrm{atm}$ & $10^{6} \mathrm{M} / \mathrm{atm}$ \\
$H_{\text {org }}$ & $\left(10^{-3}\right) H_{\mathrm{aq}}$ & $H_{\mathrm{aq}}$ \\
$k_{\mathrm{aq}}$ & $10^{2} \mathrm{~s}^{-1}$ & $5 \times 10^{6} \mathrm{~s}^{-1}$ \\
$k_{\mathrm{org}}$ & $\left(10^{-7}\right) k_{\mathrm{aq}}$ & $k_{\mathrm{aq}}$ \\
$\alpha$ & $10^{-3}$ & 1.0
\end{tabular}

be equal with that given by the traditional resistor model, demonstrating that the developed model is truly an extension of the traditional resistor formalism. Furthermore, it should be noted that eq 11 does not contain $k_{\text {org }}$, i.e., the effect of chemical reactions taking place in the organic coating is not accounted for.

To illustrate the implications of eq 11 , let us assume that gas-phase diffusion and mass accommodation do not limit the reactive uptake, the coating is relatively thin, and that $q_{\mathrm{aq}} \gg 1$. From the last assumption it follows that $Q \approx q_{\mathrm{aq}}$, and thus diffusion through an organic coating becomes the rate-limiting step when $1 / \Gamma_{\text {coat }}>1 / \Gamma_{\text {aq }}$ or when

$$
l>\frac{H_{\text {org }} D_{\text {org }}}{H_{\mathrm{aq}} \sqrt{D_{\mathrm{aq}} k_{\mathrm{aq}}}}
$$

Here we have used the assumption that $R_{\mathrm{p}} \gg l$ or $R_{\mathrm{c}} \approx R_{\mathrm{p}}$. Provided that the values of the relevant parameters can be determined or estimated, eq 12 provides a simple tool to investigate under which conditions dissolution and diffusion in a coating may limit the reactive uptake. Moreover, the coating thickness $l$ needed in order to make $1 / \Gamma_{\text {coat }}$ the largest term in eq 11 is seen to be inversely proportional to the square root of $k_{\text {aq }}$, which illustrates the point that rapid aqueous phase reactions are most susceptible to the presence of organic coatings on particles

2.3. Comparison of Various Expressions for the Uptake Coefficient. Mass transfer resistance caused by the presence of an organic coating on an aqueous aerosol has three potential sources: a reactant molecule must first accommodate into the particle surface, then dissolve into the coating, and finally diffuse to the aqueous phase. Through performing a large set of calculations we addressed the following questions: (1) under which conditions is the reactive uptake limited due to dissolution and diffusion in the coating and (2) what is the valid range of eq 11? This was done by comparing the uptake coefficients predicted by eqs 9 and 11 and by the traditional resistor model with each other. We denote these quantities as $\gamma_{\text {full }}, \gamma_{\text {mod }}$, and $\gamma_{\text {trad }}$, respectively. The parameter $\gamma_{\text {trad }}$ was calculated assuming that the organic coating has identical properties with the aqueous phase, i.e., influence of organic coatings on the reactive uptake is neglected. The molecular weight of the gaseous reactant was assumed to be $108 \mathrm{~g} / \mathrm{mol}$, and $T, D_{\text {gas }}$, and $D_{\text {aq }}$ were set equal to $298 \mathrm{~K}, 10^{-5}$, and $10^{-9} \mathrm{~m}^{2} / \mathrm{s}$, respectively. The choice of the molecular weight is motivated by the $\mathrm{N}_{2} \mathrm{O}_{5}$ heterogeneous hydrolysis on which we focus in the next section. The following results are not sensitive to the value of this parameter, however. The values of the remaining parameters $\left(R_{\mathrm{p}}, l, D_{\mathrm{org}}, H_{\mathrm{aq}}, H_{\mathrm{org}}\right.$, $k_{\text {aq }}, k_{\text {org }}$, and $\alpha$ ) were varied independently of each other so that the parameter space was covered with approximately 25000 calculations. The explored parameter range is shown in Table 1. The Kelvin effect is not accounted for in the comparison,
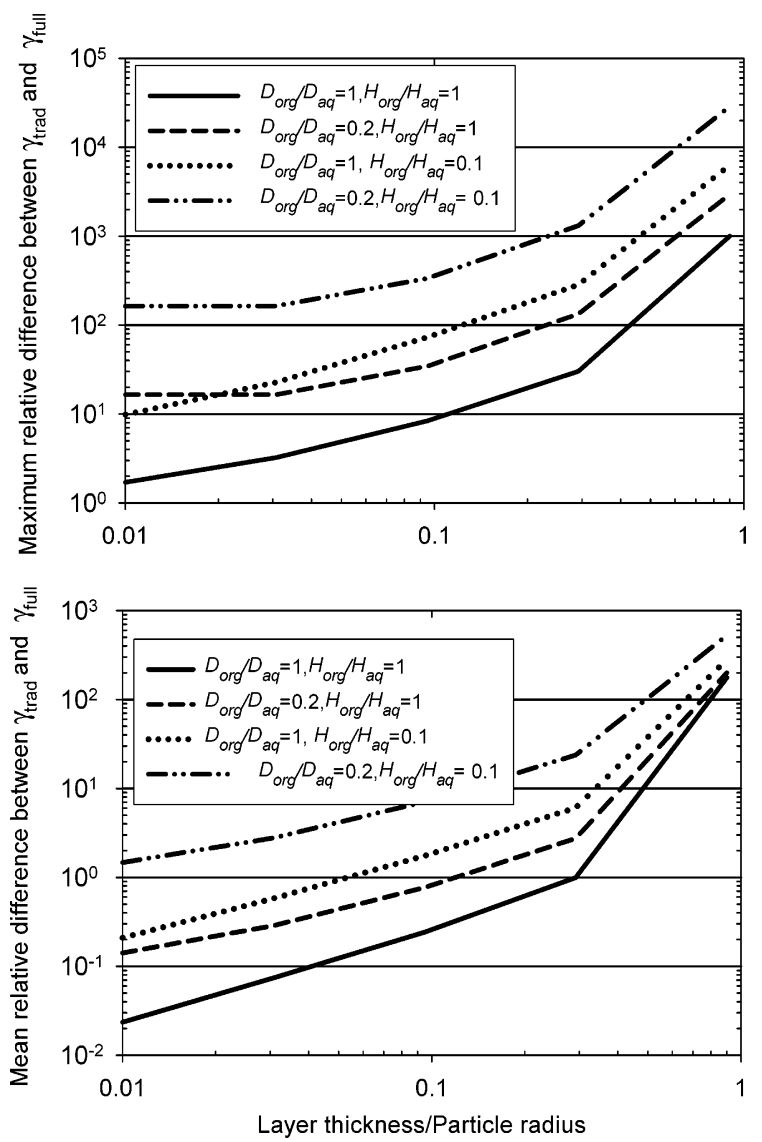

Figure 2. Maximum deviation of $\gamma_{\text {trad }}$ from $\gamma_{\text {full }}$ (top) and the mean relative difference between $\gamma_{\text {trad }}$ and $\gamma_{\text {full }}$ (bottom) as a function of the relative coating thickness $l / R_{\mathrm{p}}$. The relative difference between $\gamma_{\text {trad }}$ and $\gamma_{\text {full }}$ is here $\left.\mid\left(\gamma_{\text {trad }}-\gamma_{\text {full }}\right) / \gamma_{\text {full }}\right) \mid$, and the mean and maximum relative differences are obtained by dividing the results into groups according to the value of $l / R_{\mathrm{p}}$ and calculating these quantities for each group.

since the performed sensitivity calculations showed that it has negligible influence on the results.

Figure 2 shows that $\gamma_{\text {trad }}$ predicts consistently higher uptake rates compared to those predicted by $\gamma_{\text {full }}$. This is expected since chemical reactions were assumed to proceed at equal or lower rate in the coating than in the aqueous phase. Furthermore, the magnitude of the overprediction is strongly dependent on the relative thickness of the coating, i.e., on $l / R_{\mathrm{p}}$. The parameter $\gamma_{\text {trad }}$ gives a good approximation for $\gamma_{\text {full }}$ if the coating is relatively thin and $H_{\mathrm{org}} / H_{\mathrm{aq}}$ as well as $D_{\mathrm{org}} / D_{\text {aq }}$ are close to unity. On the other hand, if $H_{\text {org }}$ and/or $D_{\text {org }}$ are decreased by an order of magnitude or more, even nanometer-sized films may inhibit the reactive uptake, and consequently large errors are induced to the uptake rates predicted by the traditional resistor formalism.

The key assumption behind expression $11\left(\gamma_{\mathrm{mod}}\right)$ is that $q_{\mathrm{org}}$ is small compared to unity, and therefore we examined how the ratio $\gamma_{\text {full }} / \gamma_{\text {mod }}$ behaves as a function of $q_{\text {org }}$ (Figure 3). For $q_{\text {org }}<10^{-4}$, both the mean relative difference between $\gamma_{\text {full }}$ and $\gamma_{\text {mod }}$ and the maximum deviations of $\gamma_{\text {full }}$ from $\gamma_{\text {mod }}$ are seen to be extremely small, i.e., an excellent agreement between $\gamma_{\bmod }$ and $\gamma_{\text {full }}$ is reached when $q_{\text {org }}<10^{-4}$. This shows that $\gamma_{\text {mod }}$ gives a good approximation to $\gamma_{\text {full }}$ when chemical reactions taking place in the coating are slow enough. To be more precise, it was found that $\gamma_{\text {full }}$ and $\gamma_{\text {mod }}$ agree within $15 \%$ when $k_{\text {org }}<$ $0.1 \mathrm{~s}^{-1}$ (not illustrated by a figure). The deviations increase, however, with increasing value of $q_{\text {org }}$ such that the mean difference between $\gamma_{\text {mod }}$ and $\gamma_{\text {full }}$ exceeds $1 \%$ and $10 \%$ when $q_{\text {org }}$ is larger than $10^{-3}$ and unity, respectively. Moreover, 


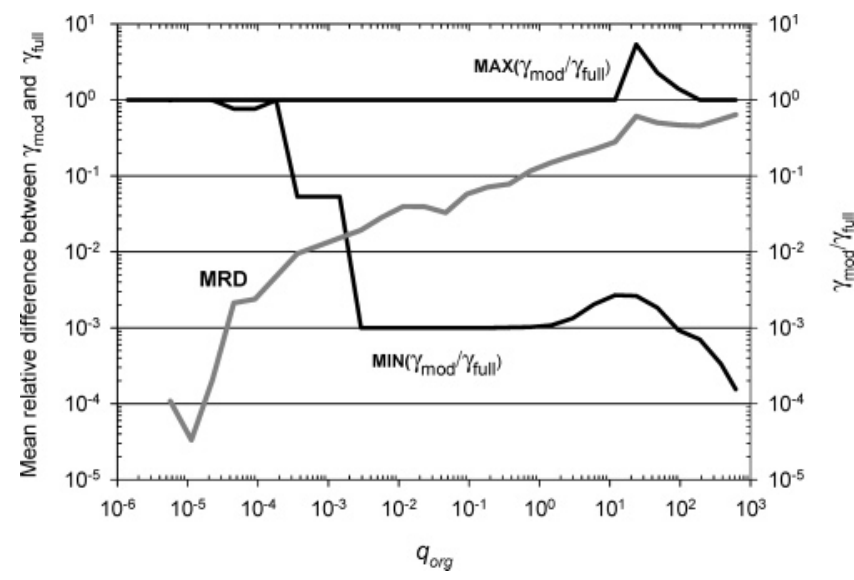

Figure 3. Mean relative difference between $\gamma_{\text {mod }}$ and $\gamma_{\text {full }}$ (MRD) (gray line) as well as the minimum and maximum values of $\gamma_{\bmod } / \gamma_{\text {full }}$, MIN$\left(\gamma_{\bmod } / \gamma_{\text {full }}\right)$, and $\operatorname{MAX}\left(\gamma_{\bmod } / \gamma_{\text {full }}\right)$ (black lines), respectively, for the performed calculations as a function of $q_{\text {org }}$. The relative difference between $\gamma_{\text {mod }}$ and $\gamma_{\text {full }}$ is defined as $\left.\mid\left(\gamma_{\text {mod }}-\gamma_{\text {full }}\right) / \gamma_{\text {full }}\right) \mid$, and the mean relative difference is obtained by dividing the calculations into groups based on the value of $q_{\text {org }}$ and calculating the average for each group. The parameters $\operatorname{MIN}\left(\gamma_{\bmod } / \gamma_{\text {full }}\right)$ and $\operatorname{MAX}\left(\gamma_{\bmod } / \gamma_{\text {full }}\right)$ are obtained in a similar fashion.

excluding some calculations in the range $10<q_{\text {org }}<200$, the maximum value of $\gamma_{\text {mod }} / \gamma_{\text {full }}$ does not exceed unity, i.e., $\gamma_{\text {mod }}$ generally underpredicts $\gamma_{\text {full. }}$. This is due to the fact that reactions taking place in the organic coating and thereby also their impact to the reactive uptake are neglected in eq 11. The accuracy of $\gamma_{\text {mod }}$ was found to be also sensitive to the relative thickness of the coating, $l / R_{\mathrm{p}}$ (Figure 4). Deviations between $\gamma_{\text {mod }}$ and $\gamma_{\text {full }}$ generally increase with an increasing value of $l / R_{\mathrm{p}}$ which is explained by the fact that the contribution of organic phase reactions to the reactive uptake, which increases with an increasing organic volume fraction, is neglected in eq 11.

\section{Application to Laboratory Data: $\mathrm{N}_{2} \mathrm{O}_{5}$ Hydrolysis in Aqueous Aerosols Coated with Monoterpene Reaction Products}

In our previous studies, we established a connection between the rate of $\mathrm{N}_{2} \mathrm{O}_{5}$ hydrolysis in organic-coated aqueous aerosols and the thickness of the coatings. ${ }^{29,30}$ Experiments were performed in the Juelich large aerosol chamber using aqueous sulfate particles as a seed aerosol, and the coatings were produced through condensation of low-volatile vapors formed through monoterpene ozonolysis. All the experiments were performed at relative humidities around $60 \%$ and at room temperatures. Furthermore, the initial monoterpene concentrations were between 10 and $40 \mathrm{ppb}$. The coating thicknesses were inferred from the performed aerosol mass spectrometer (AMS) measurements and they ranged from a few nanometers, which is more than required to form a monolayer, to around $20 \mathrm{~nm}$ in the vacuum aerodynamic diameter range of 200-600 $\mathrm{nm}$. In general, thicker coatings lead to smaller uptake coefficients of $\mathrm{N}_{2} \mathrm{O}_{5}, \gamma_{\mathrm{N}_{2} \mathrm{O}_{5}}$. We also performed two uptake experiments with part-per-million levels of $\alpha$-pinene, including one with no seed aerosol. No AMS was available during these experiments though. Overall, $\gamma_{\mathrm{N}_{2} \mathrm{O}_{5}}$ varied between $1.1 \times 10^{-2}$ and $4.5 \times$ $10^{-4}$ in these experiments, the experimental uncertainty being that of $S_{\text {tot }}$, which is determined to be better than $\pm 10 \%$ in these cases. ${ }^{31,32}$

We note that the $\mathrm{N}_{2} \mathrm{O}_{5}$ uptake coefficients were determined from the decay of $\mathrm{N}_{2} \mathrm{O}_{5}$ in the gas phase, using an expression that includes the product of $\gamma_{\mathrm{N}_{2}} \mathrm{O}_{5}$ and the total particle surface
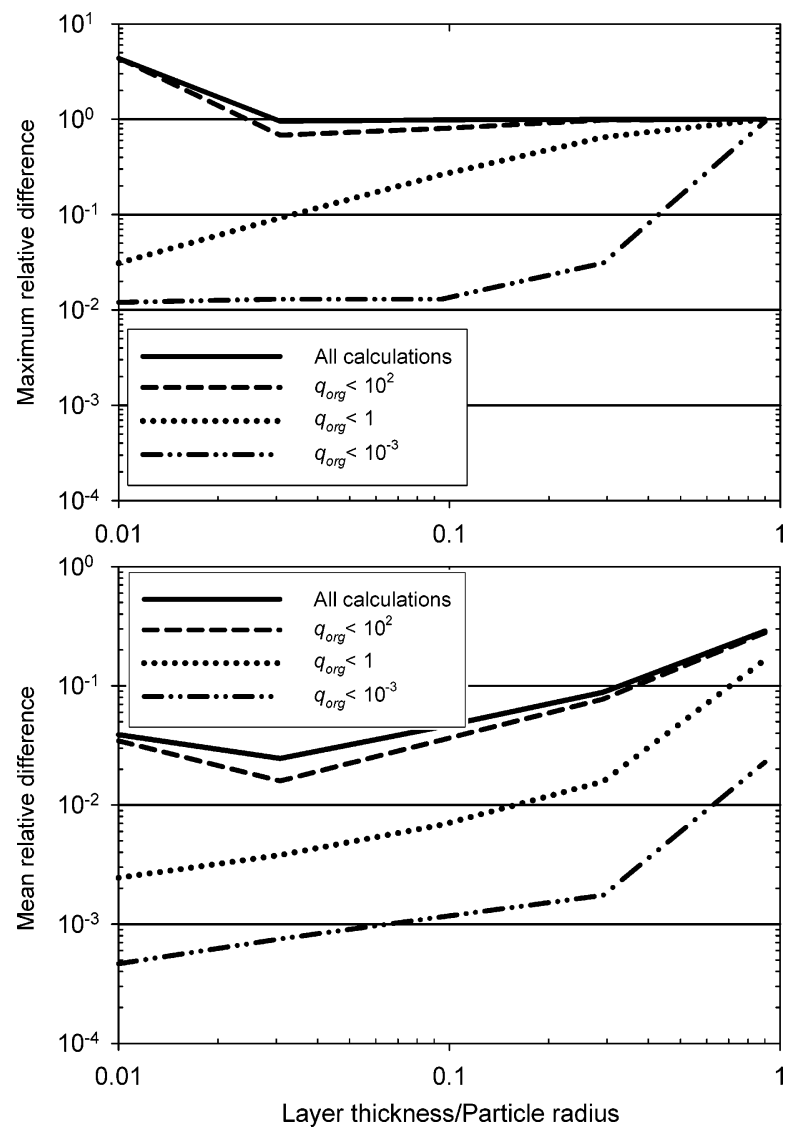

Figure 4. Maximum (top) and mean (bottom) relative difference between $\gamma_{\text {mod }}$ and $\gamma_{\text {full }}$ as a function of the relative coating thickness. The value range of $q_{\text {org }}$ over which the averaging is performed is shown in the legend.

area $S_{\text {tot. }}{ }^{12}$ All systematic errors in $S_{\text {tot }}$ will thus be inversely proportionally reflected in $\gamma_{\mathrm{N}_{2} \mathrm{O}_{5}}$. Provided that the coatings are nonreactive, the reactive surface area is the total surface area

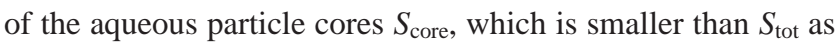
inferred from particle size distribution measurements. As shown above, the pure existence of a nonreactive film with the same properties as the aqueous core will already reduce the observed $\gamma_{\mathrm{N}_{2} \mathrm{O}_{5}}$. Since $S_{\text {core }}$ is smaller than $S_{\text {tot }}$, and thus the reactive volume in the particle is also diminished, a reduction of $\gamma_{\mathrm{N}_{2} \mathrm{O}_{5}}$ could be only apparent due to an "incorrect choice" of the reactive surface area. To estimate the upper limit of such an apparent effect, we calculated $S_{\text {core }}$ using an aerosol dynamic model ${ }^{13}$ and redetermined $\gamma_{\mathrm{N}_{2} \mathrm{O}_{5}}$ based on the predicted total core surface areas. As a result, $\gamma_{\mathrm{N}_{2} \mathrm{O}_{5}}$ decreased up to $10 \%$, which is not enough to explain the observations. In our previous study, where the coating thicknesses were not quantified with an AMS, the decreased uptake rates were attributed to a decreased solubility and/or mass accommodation coefficient of $\mathrm{N}_{2} \mathrm{O}_{5} \cdot{ }^{12}$

Here we illustrate the usefulness of the model in interpreting experimental data by attempting to explain quantitatively the observed reduction. The analysis is divided into two parts: we focus first on the experiments with relatively low monoterpene concentrations (section 3.1) and then extend the analysis to cover experiments involving high monoterpene loads (section 3.2).

3.1. Thin Coatings. To simplify the analysis we use the approximate expression for the uptake coefficient, eq 11. As will be demonstrated in section 3.2., the choice is justified since the coatings formed in these experiments were sufficiently thin and weakly reactive. 

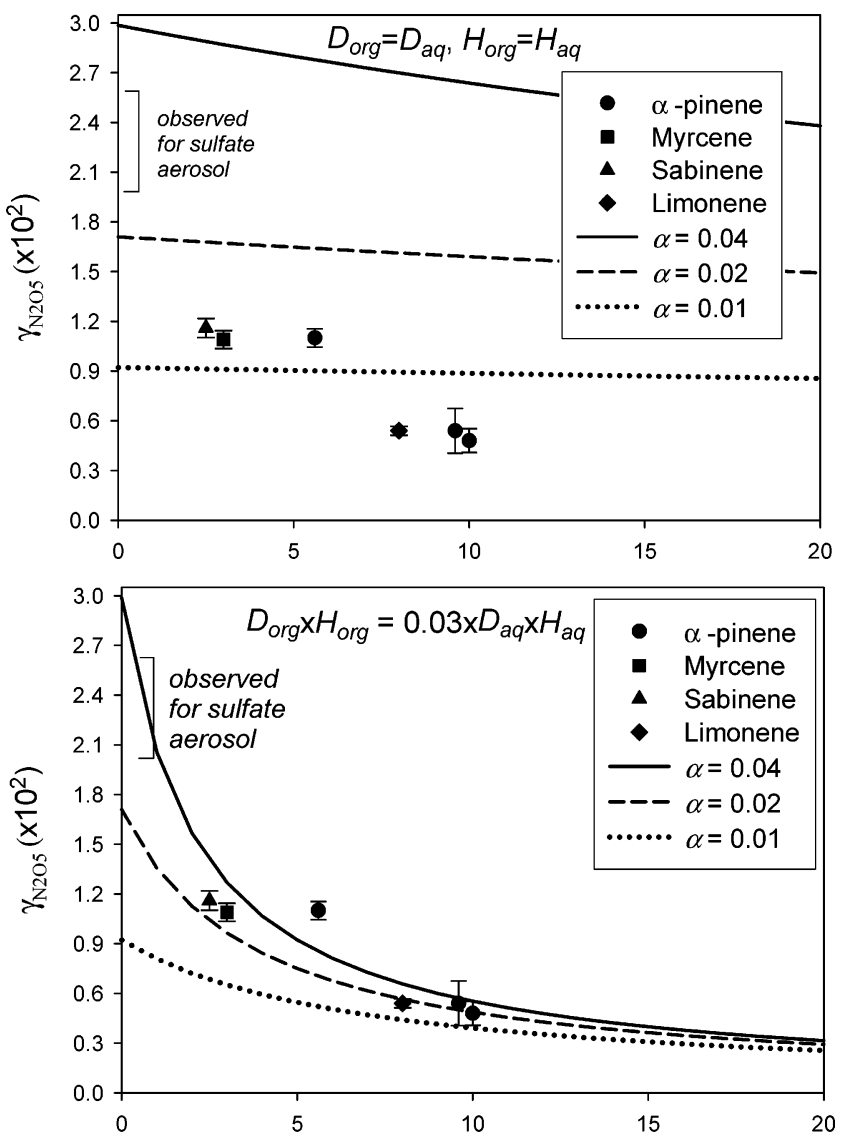

Layer thickness in particles with a diameter $600 \mathrm{~nm}$

Figure 5. Calculated (lines) and measured (symbols) uptake coefficients of $\mathrm{N}_{2} \mathrm{O}_{5}$ as a function of the coating thickness for particles having a diameter $600 \mathrm{~nm}$.

The values of the input parameters for eq 11 are chosen as follows. Because the particle surface area peaked at around 600 $\mathrm{nm}$ in the mobility diameter, the "representative" particle radius, i.e., $R_{\mathrm{p}}$ in eqs 9 and 11 , for the $\mathrm{N}_{2} \mathrm{O}_{5}$ uptake is $300 \mathrm{~nm}$. The performed sensitivity calculations showed that varying the particle radius by $20 \%$ lead to $10 \%$ changes in the predicted uptake rates at maximum. Because this range covers the peak surface diameters in the experiments the value of $R_{\mathrm{p}}$ is kept constant in the following. The values of the parameters associated with the aqueous core $\left(H_{\mathrm{aq}}, D_{\mathrm{aq}}\right.$, and $\left.k_{\mathrm{aq}}\right)$ were taken from Mentel et al. ${ }^{32}$ Even though the values of these parameters are also somewhat uncertain, the results are not very sensitive to them as shown below.

The parameters associated with an organic coating to the uptake rate are $\alpha$, the layer thickness $l$, and $H_{\text {org }} D_{\text {org }}$. Here we calculated the uptake coefficient as a function of the layer thickness and varied the values of the other two parameters to find an optimal fit to the data. The base case value of $\alpha$ was 0.04 which is the reported value for pure water surfaces. ${ }^{33}$

The experimental results and some of the performed fits are shown in Figure 5. We first note that $\gamma_{\mathrm{N}_{2} \mathrm{O}_{5}}$ is predicted to be around 0.03 in the limit where particles do not contain a coating, i.e., $l=0$. The predicted value is obtained by setting the layer thickness equal to zero in eq 11 and is roughly $15-35 \%$ higher than what was observed for aqueous, uncoated sulfate particles. Because sulfate aerosols were used as a seed in the experiments, we recalculated $\gamma_{\mathrm{N}_{2} \mathrm{O}_{5}}$ by varying the values of $H_{\mathrm{aq}}, k_{\mathrm{aq}}$, and $D_{\mathrm{aq}}$ so that $\gamma_{\mathrm{N}_{2} \mathrm{O}_{5}}$ was between 0.02 and 0.03 at $l=0$. The variation affected $\gamma_{\mathrm{N}_{2} \mathrm{O}_{5}}$ mainly at the regime $l<10 \mathrm{~nm}$, and the changes were below $15 \%$ for layer thicknesses larger than $3 \mathrm{~nm}$. The low sensitivity is explained by the fact that uptake rates were limited by mass accommodation or dissolution and diffusion in the coating. Because of the low sensitivity, the considered parameters are not varied in the following.

Nonreactive coatings that share similar properties with the aqueous phase, i.e., coatings for which $\alpha=0.04, H_{\mathrm{org}}=H_{\mathrm{aq}}$, and $D_{\text {org }}=D_{\text {aq }}$, do not provide enough mass transfer resistance to explain the observations, which is demonstrated by a clear overprediction of the experimental uptake rates (Figure 5, top). Figure 5 (top) shows also that the calculated uptake coefficients do not exhibit a notable sensitivity to the coating thickness when $H_{\text {org }}=H_{\text {aq }}$ and $D_{\text {org }}=D_{\text {aq }}$ regardless of the value of $\alpha$. Therefore a reduced mass accommodation coefficient cannot be the only reason for the decreased hydrolysis rates. Of course the structure of the coatings and hence $\alpha$ could depend on the initial monoterpene and ozone concentrations. This might take place, for example, if the reaction product distribution or the gas/particle partitioning of semivolatile oxidation products is sufficiently sensitive to the precursor concentrations. To illustrate how the model can be applied in interpreting experimental data, we assume a homogeneous $\alpha$ for monoterpene oxidation products and we attempt to fit the data for this group of compounds using a single set of parameters without changing $\alpha$ individually for each experiment. Additionally, tuning $\alpha$ to match the predictions with the observations would not provide much insight into the mechanisms behind the reduction.

We are thus left with two possible explanations: the diffusion coefficient of $\mathrm{N}_{2} \mathrm{O}_{5}$ is smaller in the coating than in the aqueous phase, i.e., $D_{\text {org }}<D_{\text {aq }}$, or $\mathrm{N}_{2} \mathrm{O}_{5}$ had a decreased solubility into the coating, i.e., $H_{\mathrm{org}}<H_{\mathrm{aq}}$. Indeed, as Figure 5 (bottom) illustrates, a good agreement between the experimental results and calculations was obtained when $\alpha$ was set to the base case value and the product $H_{\mathrm{org}} D_{\mathrm{org}}$ was decreased by a factor of approximately 30 compared to $H_{\mathrm{aq}} D_{\mathrm{aq}}$. The largest deviations from the data take place around $6 \mathrm{~nm}$ in layer thickness where the experimental uptake coefficient was underpredicted by $25 \%$. If the value of $\alpha$ is additionally decreased, the dependence of $\gamma_{\mathrm{N}_{2} \mathrm{O}_{5}}$ on the coating thickness becomes less pronounced such that the observational trend is poorly captured when the value of $\alpha$ is below 0.02 . This is because the coating thickness range where mass accommodation is the limiting step in the uptake increases with decreasing $\alpha$. For sufficiently thick coatings, however, $1 / \Gamma_{\text {coat }}$ is the dominating term in eq 11 which is seen from the convergence of the curves for varying values of $\alpha$. The calculations thus suggest that the accommodation coefficient of $\mathrm{N}_{2} \mathrm{O}_{5}$ to such an organic matrix is no more than a factor of 2 smaller than that to pure water surfaces. The sensitivity of the fits to the value of $H_{\mathrm{org}} D_{\text {org }}$ is investigated in section 3.2.

The above-presented results suggest that the coatings formed in the experiments had relatively tight structures which can effectively suppress the $\mathrm{N}_{2} \mathrm{O}_{5}$ hydrolysis. These were formed from single monoterpene precursors, whereas in the atmosphere mixtures of precursors exist. Thus, in addition we performed one experiment where an equimolar mixture of the four monoterpenes ( $\alpha$-pinene, myrcene, sabinene, limonene) with a total concentration of $12 \mathrm{ppb}$ was injected into the chamber. Although the film thickness was in the range of expectation if the sum of the individual yields is considered, the observed uptake of $\mathrm{N}_{2} \mathrm{O}_{5}\left(\gamma_{\mathrm{N}_{2} \mathrm{O}_{5}}=1.9 \times 10^{-2}\right.$, the experimental uncertainty being $\pm 10 \%$ ) was 2 or 3 times larger than expected from the experiments involving single monoterpenes and only 10-30\% smaller than $\gamma_{\mathrm{N}_{2} \mathrm{O}_{5}}$ determined for aqueous sulfate aerosols $\left(2.0-2.6 \times 10^{-2}\right)$. For the corresponding film thickness 
our model (eq 11) predicts that $H_{\mathrm{org}} D_{\mathrm{org}}$ is approximately a factor of 8 smaller than $H_{\text {aq }} D_{\text {aq }}$. Since $H_{\text {org }}$ for $\mathrm{N}_{2} \mathrm{O}_{5}$ in the mixture experiment is probably not much different from that for experiments involving individual monoterpenes, the difference can be attributed to a factor of 3-6 larger diffusion coefficient in the mixture experiment.

3.2. Thick Coatings and Pure Organic Aerosols. The analysis of the last section was based on the use of the approximate expression for the uptake coefficient, eq 11, which neglects the effect of reactions taking place in a coating and therefore requires no information on the reaction rate constant $k_{\text {org }}$. To validate the use of eq 11 and to extend the analysis to larger coating thicknesses, we utilize results from two oxidation experiments involving high monoterpene loads.

To begin with, a value of $4.5 \times 10^{-4}$ (within $10 \%$ experimental uncertainty) for the $\mathrm{N}_{2} \mathrm{O}_{5}$ uptake coefficient was determined in an experiment where no seed aerosols were injected into the chamber but particles were produced through nucleation of $\alpha$-pinene oxidation products at $60 \%$ RH. ${ }^{12}$ Since the uptake coefficients were determined from the loss rate of gaseous $\mathrm{N}_{2} \mathrm{O}_{5}$, the real uptake could be smaller due to losses of $\mathrm{N}_{2} \mathrm{O}_{5}$ to the chamber walls. Provided that $\mathrm{N}_{2} \mathrm{O}_{5}$ reacts also in purely organic aerosols (with the very small amount of residual water), however, the analysis presented in the last section needs validation since the accuracy of eq 11 depends strongly on $k_{\text {org }}$ (section 2.3). In the following, we neglect the effect of wall losses which yields an upper limit for the reactivity of $\mathrm{N}_{2} \mathrm{O}_{5}$ in such an organic media.

We performed also an experiment where $1 \mathrm{ppm}$ of $\alpha$-pinene was injected into the chamber in the presence of seed aerosols. The $\mathrm{N}_{2} \mathrm{O}_{5}$ uptake coefficient for the experiment was $5.9 \times 10^{-4}$ (within $20 \%$ experimental uncertainty) which is only $30 \%$ larger than the value of $4.5 \times 10^{-4}$ determined for secondary organic aerosol (SOA, see above). This indicates that the reactive uptake was mainly due to the organic aerosol component. We have no quantitative information on the coating thicknesses, however, since an AMS was not available during the experiment. Therefore we estimated them with a numerical model that simulates aerosol dynamics in the chamber. ${ }^{13}$ By constraining the yield of condensable oxidation products with the particle size distribution measurements, the coating thickness on 600 $\mathrm{nm}$ particles was calculated to be in the range of 110-150 nm. The estimate is based on the assumption that condensed organic material forms a separate coating on seed aerosols. In order investigate if this result is consistent with the analysis carried out in the previous section, we extended the calculations to thicker coatings using the accurate expression for the uptake coefficient, eq 9.

The values of the parameters $R_{\mathrm{p}}, k_{\mathrm{aq}}, D_{\mathrm{aq}}$, and $H_{\mathrm{aq}}$, were chosen as in the last section. The values of the remaining parameters $\alpha, H_{\text {org }}, D_{\text {org }}$, and $k_{\text {org }}$ were varied to find an optimal fit to the data, the only restriction being that eq 9 was forced to produce the experimentally determined $\gamma_{\mathrm{N}_{2} \mathrm{O}_{5}}, 4.5 \times 10^{-4}$, at the limit of pure SOA. It was found out that consequently the product $H_{\mathrm{org}} D_{\text {org }}$ governs the value $\gamma_{\mathrm{N}_{2}} \mathrm{O}_{5}$ rather than the values of the individual parameters, and therefore we report only the value of the product.

Figure 6 shows several things. First, $\gamma_{\mathrm{N}_{2} \mathrm{O}_{5}}$ calculated using eqs 9 and 11 are in an excellent agreement in the coating thickness range $<20 \mathrm{~nm}$, justifying the use of eq 11 in the last section. When the coating thickness increases, however, the fits based on eq 11 start to deviate from those obtained using eq 9 , illustrating the fact that eq 11 is not applicable to sufficiently thick coatings even though they would be only weakly reactive.

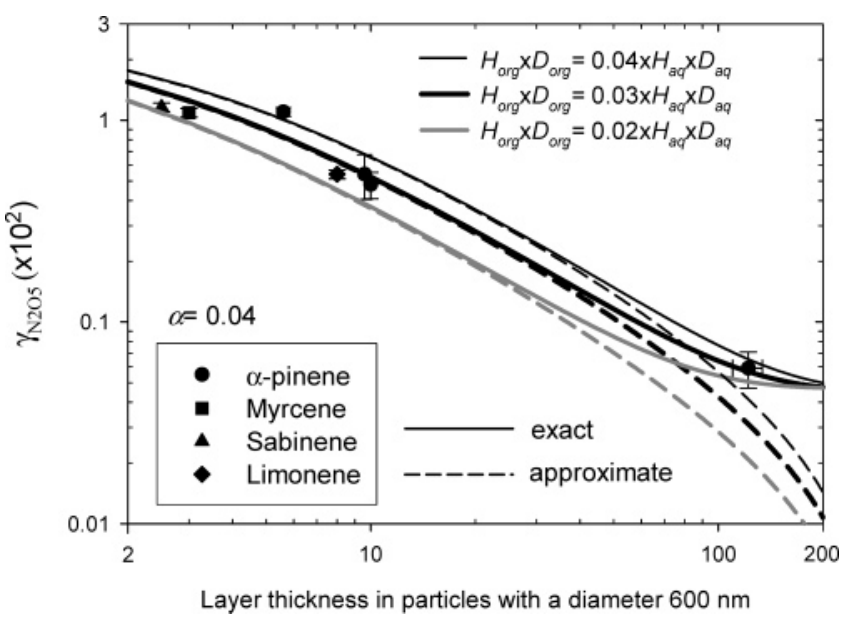

Figure 6. Calculated (lines) and measured (symbols) uptake coefficients of $\mathrm{N}_{2} \mathrm{O}_{5}$ as a function of the coating thickness for particles having a diameter $600 \mathrm{~nm}$. Solid and dashed lines indicate calculations based on eqs 11 and 9, respectively. The mass accommodation coefficient was set equal to that for pure water.

Moreover, the fits based on eq 9 are seen to be in a reasonable agreement with the entire data set using the chosen values of $H_{\text {org }} D_{\text {org }}$ and $\alpha$. The fits become independent of the value of $H_{\text {org }} D_{\text {org }}$ when the coating thickness approaches $200 \mathrm{~nm}$ because the calculations produce the experimental value of $\gamma_{\mathrm{N}_{2}} \mathrm{O}_{5}$ for pure SOA and because aerosols having such thick coatings are composed mainly of organics.

Table 2 summarizes results from a larger set of model calculations, showing that the best agreement with the data is reached when $\alpha$ is in the range of $0.02-0.04$ and when $H_{\text {org }} D_{\text {org }}$ is approximately a factor of 20-35 smaller than $H_{\mathrm{aq}} D_{\mathrm{aq}}$. The root-mean-square error was between 1.2 and $3.8 \times 10^{-3}$ for these cases, and the maximum relative errors were between $44 \%$ and $77 \%$ for the whole data set and between $25 \%$ and $70 \%$ for thin coatings. The largest errors occur typically with the experiment with $1.22 \mathrm{ppm} \alpha$-pinene, for which the uncertainties were also largest (Figure 6). As also seen from Table 2, the agreement between the data and the fits was consistently worse when the values of the parameters were outside the mentioned range.

We would like to remind the reader that the analysis is based on a limited data set consisting of eight experiments with four different precursors, causing inevitably some uncertainties to the estimates. For this reason, the analysis should not be viewed as an attempt to validate the model but as an illustration of its usefulness in interpreting experimental data. Nevertheless, the data set spans a large coating thickness range ranging from a few nanometers to $>100 \mathrm{~nm}$ over which the uptake coefficients vary more than 1 order of magnitude. When the optimal values for parameters were used, the model reproduced the experimental uptake coefficients within $25 \%$ for thin coatings and within $66 \%$ for the whole data set (Table 2), which can be considered as sufficient agreement for our purposes.

\section{Discussion}

A potential application of the parametrization are model studies investigating the heterogeneous $\mathrm{N}_{2} \mathrm{O}_{5}$ hydrolysis, which plays an important role in atmospheric $\mathrm{NO}_{x}$ removal. ${ }^{35,36}$ The impact is yet poorly constrained due to the sensitivity of $\gamma_{\mathrm{N}_{2} \mathrm{O}_{5}}$ to the size, phase, and chemical composition of aerosols, ${ }^{32,37-41}$ and therefore parametrizations accounting for the complexity of atmospheric aerosol are needed. ${ }^{36}$ In fact, recent aircraft measurements show that $\gamma_{\mathrm{N}_{2}} \mathrm{O}_{5}$ varies in the atmosphere more 
TABLE 2: Summary of the Results from a Set of Model Calculations $^{a}$

\begin{tabular}{|c|c|c|c|c|}
\hline $\begin{array}{l}k_{\text {org }} \\
\left(\mathrm{s}^{-1}\right)\end{array}$ & $\begin{array}{c}\left(D_{\mathrm{org}} H_{\mathrm{org}}\right) / \\
\left(D_{\mathrm{aq}} H_{\mathrm{aq}}\right)\end{array}$ & $\begin{array}{c}\text { rms error } \\
\left(\times 10^{2}\right)\end{array}$ & $\begin{array}{c}\text { MRE excluding } \\
\text { the experiment } \\
\text { with } 1.2 \mathrm{ppm} \\
\alpha \text {-pinene }\end{array}$ & $\begin{array}{c}\text { MRE including } \\
\text { the experiment } \\
\text { with } 1.2 \mathrm{ppm} \\
\alpha \text {-pinene }\end{array}$ \\
\hline \multicolumn{5}{|c|}{$\alpha=0.04$} \\
\hline 20 & 1.0 & 1.8 & 4.42 & 7.23 \\
\hline 70 & 0.1 & 0.79 & 1.60 & 1.60 \\
\hline 90 & $5.0 \times 10^{-2}$ & 0.38 & 0.70 & 0.70 \\
\hline 100 & $4.0 \times 10^{-2}$ & 0.26 & 0.45 & 0.54 \\
\hline 120 & $3.0 \times 10^{-2}$ & 0.15 & 0.24 & 0.66 \\
\hline 150 & $2.0 \times 10^{-2}$ & 0.21 & 0.45 & 0.77 \\
\hline 210 & $1.0 \times 10^{-2}$ & 0.21 & 0.69 & 0.88 \\
\hline 700 & $1.0 \times 10^{-3}$ & 0.76 & 1.00 & 0.98 \\
\hline \multicolumn{5}{|c|}{$\alpha=0.03$} \\
\hline 20 & 1.0 & 1.34 & 3.41 & 6.91 \\
\hline 70 & 0.1 & 0.59 & 1.33 & 1.33 \\
\hline 100 & $5.0 \times 10^{-2}$ & 0.26 & 0.58 & 0.58 \\
\hline 110 & $4.0 \times 10^{-2}$ & 0.18 & 0.36 & 0.55 \\
\hline 120 & $3.0 \times 10^{-2}$ & 0.13 & 0.44 & 0.66 \\
\hline 140 & $2.0 \times 10^{-2}$ & 0.23 & 0.47 & 0.77 \\
\hline 210 & $1.0 \times 10^{-2}$ & 0.45 & 0.70 & 0.88 \\
\hline 700 & $1 \times 10^{-3}$ & 0.76 & 0.99 & 0.99 \\
\hline \multicolumn{5}{|c|}{$\alpha=0.02$} \\
\hline 20 & 1.0 & 0.80 & 2.29 & 6.34 \\
\hline 70 & 0.1 & 0.34 & 0.97 & 0.97 \\
\hline 90 & $5.0 \times 10^{-2}$ & 0.14 & 0.44 & 0.44 \\
\hline 100 & $4.0 \times 10^{-2}$ & 0.12 & 0.27 & 0.55 \\
\hline 120 & $3.0 \times 10^{-2}$ & 0.17 & 0.38 & 0.66 \\
\hline 150 & $2.0 \times 10^{-2}$ & 0.29 & 0.52 & 0.77 \\
\hline 210 & $1.0 \times 10^{-2}$ & 0.48 & 0.72 & 0.88 \\
\hline 700 & $1 \times 10^{-3}$ & 0.76 & 0.97 & 0.97 \\
\hline \multicolumn{5}{|c|}{$\alpha=0.01$} \\
\hline 21 & 1.0 & 0.30 & 0.84 & 5.03 \\
\hline 70 & 0.1 & 0.23 & 0.37 & 0.34 \\
\hline 90 & $5.0 \times 10^{-2}$ & 0.27 & 0.43 & 0.45 \\
\hline 100 & $4.0 \times 10^{-2}$ & 0.30 & 0.48 & 0.56 \\
\hline 120 & $3.0 \times 10^{-2}$ & 0.34 & 0.54 & 0.66 \\
\hline 150 & $2.0 \times 10^{-2}$ & 0.41 & 0.62 & 0.77 \\
\hline 210 & $1.0 \times 10^{-2}$ & 0.54 & 0.75 & 0.88 \\
\hline 700 & $1 \times 10^{-3}$ & 0.76 & 0.97 & 0.99 \\
\hline
\end{tabular}

${ }^{a}$ The values of $k_{\text {org }}$ and $D_{\text {org }} H_{\text {org }}$ used in the calculations are shown. The rms error refers to the root-mean-square error in the calculated uptake coefficients, and MRE refers to the maximum relative error. The calculation with the smallest rms error is shown in bold for each considered value of $\alpha$.

than the uptake parametrizations used in the state-of-the-art atmospheric models suggest. ${ }^{42}$ One reason for this discrepancy is the presence of organic films on the particles. ${ }^{12,42}$ So far organic coatings have not been included in the atmospheric models, but the framework derived here, in particular eq 11, provides a parametrization for coatings which are sufficiently thick to be considered as a continuous media.

The analysis carried out in section 3.2 suggests that organic coatings formed through monoterpene oxidation have such properties that the $\mathrm{N}_{2} \mathrm{O}_{5}$ hydrolysis rate is reduced significantly in areas with high biogenic emissions. It should be kept in mind, however, that the coatings in the analyzed experiments were formed through ozonolysis of single monoterpenes, four different though, whereas the atmosphere contains a wide mix of various monoterpenes. In fact, the value of $\gamma_{\mathrm{N}_{2} \mathrm{O}_{5}}$ determined in the experiment involving a mixture of four monoterpenes (section 3.1) is closer to aqueous inorganic and water-soluble organic systems. ${ }^{30}$ This observation would be in accordance with the hypothesis of extended films, as proposed by Gill et al., ${ }^{34}$ less efficiently packed structures that are likely to be formed from normally complex atmospheric mixtures of organic compounds. On the other hand, Folkers et al. ${ }^{12}$ observed large reductions of $\gamma_{\mathrm{N}_{2} \mathrm{O}_{5}}\left(\gamma_{\mathrm{N}_{2} \mathrm{O}_{5}}=3-6 \times 10^{-3}\right)$ by ozonolysis of particle-filtered outside air, containing a mixture of biogenic and anthropogenic VOCs characteristic to a semirural area, in the presence of sulfate seed aerosols. These results show that atmospheric organic compounds exhibit a wide range of behavior, and therefore the impact of monoterpene oxidation for mixtures of monoterpenes on the atmospheric heterogeneous hydrolysis of $\mathrm{N}_{2} \mathrm{O}_{5}$ should still be regarded as an open question. Moreover, the results highlight that laboratory studies investigating SOA formation from the oxidation of an individual hydrocarbon may produce results that are misleading considering the atmospheric conditions. Therefore, more emphasis should be put on experimental studies that aim to identify and investigate atmospherically relevant mixtures.

\section{Summary and Conclusions}

To comprehensively account for the mechanisms through which multilayered organic coatings may slow the reactive uptake by aqueous aerosols, an extension of the so-called resistor model was derived. The extension accounts for dissolution, diffusion, and chemical reaction $\mathrm{s}$ in a coating. To facilitate interpretation of experimental data and to provide a parametrization for large-scale models, an approximate expression for the uptake coefficient was derived for weakly and nonreactive coatings. The validity of the approximate expression was assessed by comparing its predictions with those given by the accurate expression. Moreover, we investigated under which conditions dissolution and diffusion in a coating limits the reactive uptake. It was shown that these processes have a negligible influence if the coating is relatively thin and the gas/ organic partitioning coefficient $\left(H_{\text {org }}\right)$ as well as the diffusion coefficient of the reactant in the organic phase $\left(D_{\text {org }}\right)$ have similar magnitude with the corresponding parameters for the aqueous phase. On the other hand, if $H_{\text {org }}$ and/or $D_{\text {org }}$ are at least 1 order of magnitude smaller, even nanometer-sized films may inhibit the reactive uptake. In this regard, rapid aqueous phase reactions were proven to be most susceptible, e.g., the $\mathrm{N}_{2} \mathrm{O}_{5}$ heterogeneous hydrolysis, which motivates further studies regarding the impact of the presence of organic coatings on particles to the atmospheric chemistry.

The developed model was also applied to explain the suppression of $\mathrm{N}_{2} \mathrm{O}_{5}$ hydrolysis in aqueous aerosols coated with monoterpene oxidation products. The coating thicknesses, inferred from the performed aerosol mass spectrometer measurements, corresponded to that of a few monolayers at least. The $\mathrm{N}_{2} \mathrm{O}_{5}$ uptake coefficients $\gamma_{\mathrm{N}_{2} \mathrm{O}_{5}}$ varied between $1.1 \times 10^{-2}$ and $5.9 \times 10^{-4}$, and thicker coatings lead generally to smaller uptake rates. Performed calculations suggested that the reaction rate constant of $\mathrm{N}_{2} \mathrm{O}_{5}$ in the coating is decreased by 3-5 orders of magnitude, in addition to which the product of the solubility of $\mathrm{N}_{2} \mathrm{O}_{5}$ and its diffusion coefficient in the coating is reduced more than an order of magnitude compared to the corresponding value for the aqueous phase. Moreover, the results suggest that the accommodation coefficient of $\mathrm{N}_{2} \mathrm{O}_{5}$ to such an organic surface is no more than a factor of 2 smaller than that to pure water surfaces. In addition to these experiments where coatings were produced through ozonolysis of an individual monoterpene, we performed an experiment involving an equimolar mixture of four monoterpenes. Experimental observation and modeling within the proposed framework suggest that the oxidation of the mixture leads to formation of more extended films that are not able to suppress the $\mathrm{N}_{2} \mathrm{O}_{5}$ hydrolysis effectively. As a conclusion, laboratory studies investigating SOA formation from 
oxidation of a single hydrocarbon may produce results that are not entirely representative to the atmosphere, and therefore more experimental studies involving various hydrocarbon mixtures are needed.

Acknowledgment. This work is part of the CASOMIO project and is supported by the EC (Contract No. EVK2-CT2001-00124). One of the authors (T.A.) gratefully acknowledges the financial support from the Helsingin Sanomat Centennial Foundation.

\section{References and Notes}

(1) Hu, Y.; Stamnes, K. Tellus 2000, 52B, 81

(2) Lohmann, U.; Feichter, J. Atmos. Chem. Phys. 2005, 5, 715.

(3) Chen, Y.; Penner, J. E. Atmos. Chem. Phys. 2005, 5, 2935.

(4) Fuzzi, S.; Andreae, M. O.; Huebert, B. J.; Kulmala, M.; Bond, T. C.; Boy, M.; Doherty, S. J.; Guenther, A.; Kanakidou, M.; Kawamura, K.; Kerminen, V.-M.; Lohmann, U.; Russell, L. M.; Pöschl, U. Atmos. Chem. Phys. 2006, 6, 2017.

(5) McFiggans, G.; Artaxo, P.; Baltensperger, U.; Coe, H.; Facchini, M. C.; Feingold, G.; Fuzzi, S.; Gysel, M.; Laaksonen, A.; Lohmann, U.; Mentel, T. F.; Murphy, D. M.; O’Dowd, C. D.; Snider, J. R.; Weingartner, E. Atmos. Chem. Phys. Discuss. 2005, 5, 8507.

(6) Ellison, G.; Tuck, A.; Vaida, V. J. Geophys. Res. 1999, 104, 11 $633-11641$.

(7) Tervahattu, H.; Hartonen, K.; Kerminen, V.-M.; Kupiainen, K.; Aarnio, P.; Koskentalo, T.; Tuck, A. F.; Vaida, V. J. Geophys. Res. 2002a, 107, doi: 19.1029/2000JD000282.

(8) Tervahattu, H.; Juhanoja, J.; Kupiainen, K. J. Geophys. Res. 2002b, 107, doi: 10.1029/2001JD001403.

(9) Mochida, M.; Kitamori, Y.; Kawamura, K.; Nojiri, Y.; Suzuki, K. J. Geophys. Res. 2002, 107, doi: 10.1029/2001JD4325.

(10) Russell, L. M.; Maria, S. F.; Myneni, S. C. B. Geophys. Res. Lett. 2002, 29, doi: 10.1029/2002GL014874.

(11) Tervahattu, H.; Juhanoja, J.; Vaida, V.; Tuck, A. F.; Niemi, J. V.; Kupiainen, K.; Kulmala, M.; Vehkamaki, H. J. Geophys. Res. 2005, 110, D06207.

(12) Folkers, M.; Mentel, T. F.; Wahner, A. Geophys. Res. Lett. 2003, 30, doi: 10.1029/2003GL017168.

(13) Anttila, T.; Kiendler-Scharr, A.; Mentel, T. F.; Tillmann, R. J. Atmos. Chem., submitted for publication, 2005.

(14) Feingold, G.; Chuang, P. Y. J. Atmos. Sci. 2000, 59, 2006.

(15) Rudich, Y. Chem. Rev. 2003, 103, 5097.

(16) Podzimek, J.; Saad, A. N. J. Geophys. Res. 1975, 80, 3386

(17) Chuang, P. Y. J. Geophys. Res. 2003, 108, doi: 10.1029/ 2002JD002757.

(18) Hanson, D. R.; Ravishankara, A. R.; Solomon., R. J. Geophys. Res. 1994, 102,9375 .
(19) Ravishankara, A. R. Science 1997, 276, 1058

(20) Seinfeld, J. H.; Pandis, S. N. Atmospheric Chemistry and Physics: From Air Pollution to Climate Change; John Wiley: New York, 1998.

(21) Kolb, C. E.; Davidovits, P.; Jayne, J. T.; Shi, Q.; Worsnop, D. R. Prog. Reac. Kinet. Mech. 2002, 27, 1.

(22) Worsnop, D. R.; Morris, J. W.; Shi, Q.; Davidovits, P.; Kolb, C. E. Geophys. Res. Lett. 2002, 29, doi: 10.1029/2002GL015542.

(23) Thornton, J. A.; Abbatt, J. P. D. J. Phys. Chem. A 2005, 109, 10004.

(24) McNeill, V. F.; Patterson, J.; Wolfe, G. M.; Thornton, J. A. Atmos. Chem. Phys. Discuss. 2006, 6, 17.

(25) Pöschl, U.; Rudich, Y.; Ammann, M. Atmos. Chem. Phys. Discuss. 2005, 5, 2111.

(26) Worsnop, D. R.; Shi, Q.; Jayne, J. T.; Kolb, C. E.; Swartz, E.; Davidovits, P. J. Aerosol. Sci. 2001, 32, 877.

(27) Smith, G. D.; Woods, E.; Baer, T.; Miller, R. E. J. Phys. Chem. A 2003, 107,9582 .

(28) Anttila, T.; Kerminen, V.-M. J. Geophys. Res. 2003, 108, doi: 10.1029/2002JD002764.

(29) Mentel, T. F.; ten Brink, H. M.; Cox, R. A.; Kulmala, M. CASOMIO, Final report; EC Contract No. EVK2-CT-2001-00124, Brussels, 2005.

(30) Kiendler-Scharr, A.; Mentel, T. F.; Folkers, M.; Henk, H. Report Series in Aerosol Science, Reissell, A., Aarflot, A., Eds.; Proceedings of the 1st iLEAPS Science Conference, Boulder, Colorado, Jan 21-26, 2006 Finnish Association for Aerosol Research: Helsinki, Finland, 2006.

(31) Folkers, M. Bestimmung der Reaktionswahrscheinlichkeit von N2O5 an troposhärisch relevanten Aerosolen. Ph.D. Thesis, Universität Köln, 2002.

(32) Mentel, T. F.; Sohn, M.; Wahner, A. Phys. Chem. Chem. Phys. 1999, $1,5451$.

(33) Van Doren, J. M.; Watson, L. R.; Davidovits, P.; Worsnop, D. R.; Zahniser, M. S.; Kolb, C. E. J. Phys. Chem. 1990, 94, 3265.

(34) Gill, P. S.; Graedel, T. E.; Weschler, C. J. Rev. Geophys. Space Phys. 1983, 21, 903.

(35) Dentener, F. J.; Crutzen, P. J. J. Geophys. Res. 1993, 98, 7149.

(36) Evans, M. J.; Jacob, D. J. Geophys. Res. Lett. 2005, 32, doi: 10.1029/2005GL022469.

(37) Robinson, G. N.; Worsnop, D. R.; Jayne, J. T.; Kolb, C. E; Davidovits, P. J. Geophys. Res. 1997, 102, 3538.

(38) Kane, S. M.; Caloz, F.; Leu, M. T. J. Phys. Chem. 2005, 105, 6465.

(39) Hallquist, M.; Stewart, D. J.; Stephenson, S. K.; Cox, R. A. Phys. Chem. Chem. Phys. 2003, 5, 3453.

(40) Thornton, J. A.; Braban, C. F.; Abbatt, J. P. D. Phys. Chem. Chem. Phys. 2003, 5, 4593.

(41) Stewart, D. J.; Griffiths, P. T.; Cox, R. A. Atmos. Chem. Phys. 2004, 4, 1381.

(42) Brown, S. S.; Ryerson, T. B.; Wollny, A. G.; Brock, C. A.; Peltier, R.; Sullivan, A. P.; Weber, R. J.; Dubé, W. P.; Trainer, M.; Meagher, J. F.; Fehsenfeld, F. C.; Ravishankara, A. R. Science 2006, 311, 67. 